\title{
EFFECT OF DIFFERENT SYMMETRIC SLITS ON MICROSTRIP PATCH ANTENNA
}

\author{
Suvidya Pawar ${ }^{1}$, R. Sreemathy ${ }^{2}$ and Shahadev Hake ${ }^{3}$ \\ ${ }^{123}$ Department of Electronics and Telecommunication Engineering, Pune Institute of \\ Computer Technology, affiliated to Savitribai Phule Pune University, Pune, India
}

\begin{abstract}
In this paper, a basic linearly polarised microstrip square patch antenna operating at $2.4 \mathrm{GHz}$ is proposed. We have modified the basic microstrip square patch antenna with rectangular shape slits, $V$ shape slits and truncated corners to achieve circular polarization. Basically we have designed five different antennas to meet the specification. The various antennas have been simulated, fabricated and the performance has been tested on network analyser (Agilent Technologies: N9912A, SNMY51464189, ROHDE \& SCHWARZ: ZVL13, $9 \mathrm{KHz}$ to $13.6 \mathrm{GHz}$,). The simulated and tested performance shows close agreement with each other. The various structures used in this study are microstrip square patch radiator, microstrip square patch radiator with truncated corner, rectangular slits, truncated corner with rectangular slits and $V$ shape slits. The experiment results show rectangular slits with truncated corners in the main square patch and rectangular slits in the main square patch provide better performance with respect to the antenna parameters. Designed antenna is compact and provides circular polarization at the required operating frequency of $2.4 \mathrm{GHz}$ with improved bandwidth and gain. The use of circularly polarized antennas presents an attractive solution to achieve this polarization match which allows for more flexibility in the angle between transmitting and receiving antennas. It gives the following advantages such as reduction in the effect of multipath reflections, decrease in transmission losses, enhancement of weather penetration and allowing any orientation to the communication system.
\end{abstract}

\section{KEYWORDS}

Wireless, microstrip antenna, circular polarization, slit.

\section{INTRODUCTION}

Communication technology and the relevant techniques are changing drastically these days. Hence we require more sophisticated wireless communication equipment's. The radio frequency utilized by the system decides its range and the scalability [1,2]. Different symmetric shaped slotted microstrip patch antennas are proposed for circular polarization for radio frequency identification applications [3]. Modern communication systems like cellular phones, personal computer cards for wireless local area networks (WLAN) prefer microstrip antennas over other radiators. These antennas provide advantages such as their light weight, low cost, low profile and uncomplicated integration with circuit components of portable personal equipment's.

Circularly polarized radiation can be generated with a symmetric slit on patch radiator having a compact size [1, 4-7]. Compact circularly polarized microstrip antennas (CPMAs) are fundamental requirement for applications such as cellular networks, radio-frequency identification (RFID) handheld readers, wireless LANs, receiver antennas for medical implants and portable wireless devices because the overall antenna size is a major consideration for such application [8-10]. Microstrip antennas are designed such that they have conducting patch 
printed on a grounded microwave substrate giving attractive features of low profile and conformability to mounting hosts.

CPMA using single feed technique does not require an external polarizer hence uses less board space than dual feed CPMA giving advantages of simple structure and compactness. Various reports in the literature have discussed many designs of single-feed, CPMAs with square or circular patches having compact size at a fixed frequency of operation [9-14]. In these designs, various compact $\mathrm{CP}$ techniques such as embedding a Y-shaped slot of unequal arm lengths, truncating patch corners or tips, inserting slits or spur lines at the patch boundary, embedding a cross slot of unequal arm lengths. These compact CP designs are fed by a probe feed or an edgefed microstrip line. Designs applied to a corner-truncated square microstrip antenna are presented in detail $[15,16]$. CP radiation of microstrip antenna operated at the TM11 mode has been accomplished for the case of a pair of slits. [16-17].

\section{STRUCTURE AND DeSIGN}

\subsection{Specifications of the design}

Square microstrip patch antenna is designed with following procedure [16, 17].

$$
\begin{gathered}
W=\frac{1}{2 f_{r} \sqrt{\mu_{0} \varepsilon_{0}}} \sqrt{\frac{2}{\varepsilon_{r}+1}}=\frac{v_{0}}{2 f_{r}} \sqrt{\frac{2}{\varepsilon_{r}+1}} \\
\varepsilon_{\text {reff }}=\frac{\varepsilon_{r}+1}{2}+\frac{\varepsilon_{r}-1}{2}\left[1+12 \frac{h}{w}\right]^{-0.5}
\end{gathered}
$$

Where, $v_{0}$ show the free-space velocity of light. Effective dielectric constant of the microstrip antenna is determined using (2), Once W is calculated determine the extension of the length $\Delta \mathrm{L}$ using

$$
\begin{gathered}
\Delta L=h\left[0.412 \frac{\left(\varepsilon_{\text {reff }}+0.3\right)\left(\frac{W}{h}+0.264\right)}{\left(\varepsilon_{\text {reff }}-0.258\right)\left(\frac{W}{h}+0.8\right)}\right] \\
L=\frac{1}{2 f_{r} \sqrt{\mu_{0} \varepsilon_{0}} \sqrt{\varepsilon_{r e f f}}}-2 \Delta L
\end{gathered}
$$

\subsection{Design Parameter}

By introducing a perturbation in the form of truncating two opposite edges and also adding slits to a basic square patch antenna circular polarization is achieved. For square, elliptical and circular microstrip patch antenna, the use of truncated edges and slits gives circular polarization. Design structure for circular polarization with truncated corners and different slit shapes inserted in main square patch was obtained. 
All the results are calculated using 3D software HFSS v.11 which is based on FEM (Finite Element Method). Results that are considered for analyses of these designed antennas are return loss, voltage standing wave ration (VSWR), axial ratio etc. These results are considered as reference for comparison with corresponding measured results of the fabricated antennas that has been designed in this work. The table 1 shows design parameter using the design procedure to construct the main square patch antenna on HFSS software.

Table 1. Design Parameter for main square patch antenna

\begin{tabular}{|l|l|}
\hline Patch Parameter & Value \\
\hline Shape & Square \\
\hline Length & 29.44 \\
\hline Length of Substrate & 39.04 \\
\hline Height of substrate & $1.6 \mathrm{~mm}$ \\
\hline Center Frequency & $2.4 \mathrm{GHz}$ \\
\hline Dielectric constant : FR4 & 4.4 \\
\hline Feeding method & Coaxial Probe Feed \\
\hline Position of Probe Feed & $7.6 \mathrm{~mm}$ in Y direction \\
\hline
\end{tabular}

The square patch antenna is shown in figure 1 with their patch and substrate dimension; Figure 2 shows cross sectional view of antenna on HFSS software. Figure 3 shows top view of an antenna on HFSS as well as the fabricated version of the same.

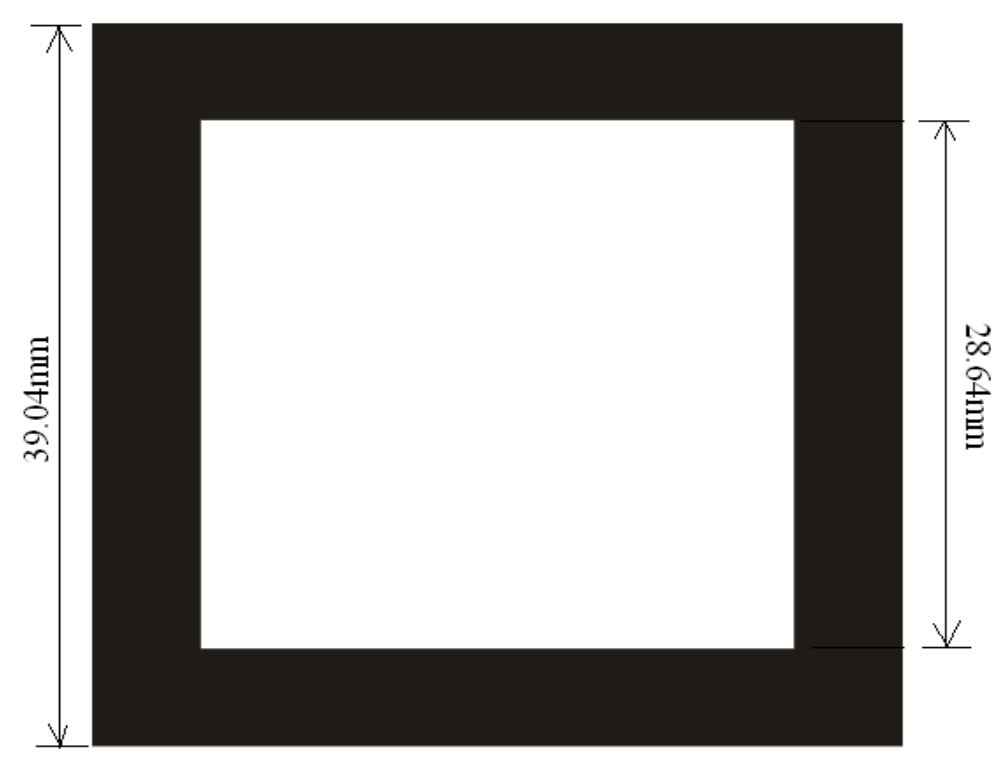

Figure 1. Microstrip square Patch Radiator 


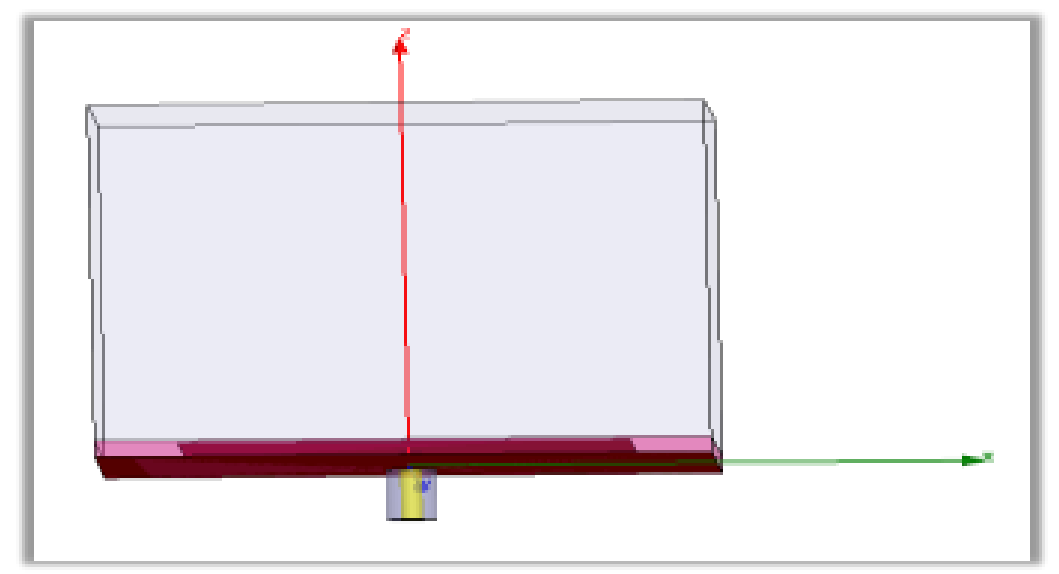

Figure 2. Cross Sectional View
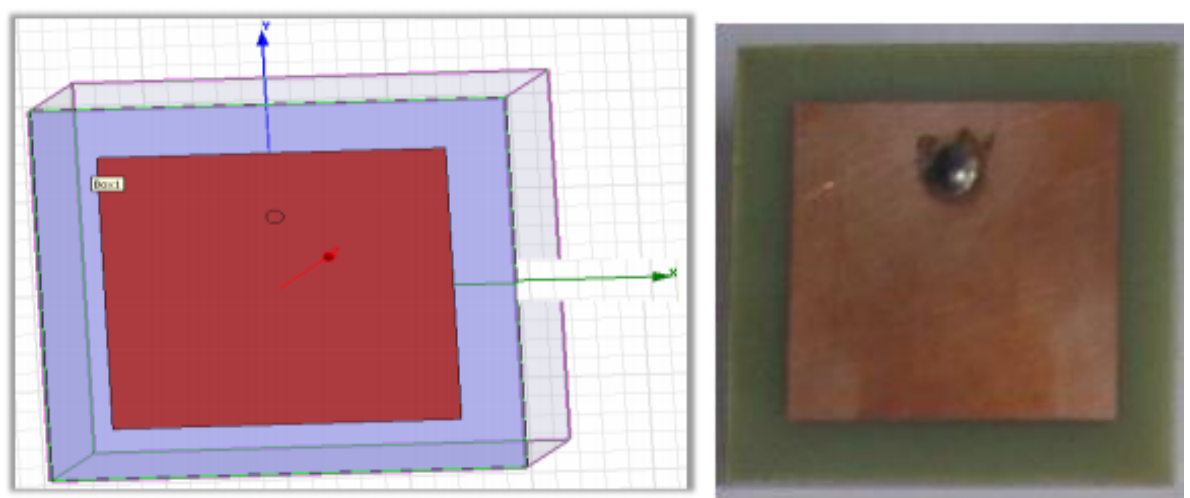

Figure 3. Microstrip square Patch Radiator

Finally we obtain the design structure for linear polarization with square patch antenna in simulated environment and in fabricated environment shown in figure 3 and for circular polarization with adding the different shaped slits shown in figure 4 to 7 in a main square patch antenna for the simulated and fabricated environment. Optimizing the truncated corner with one diagonal and also optimizing the different slit shape with one diagonal or both diagonals offer the best results.
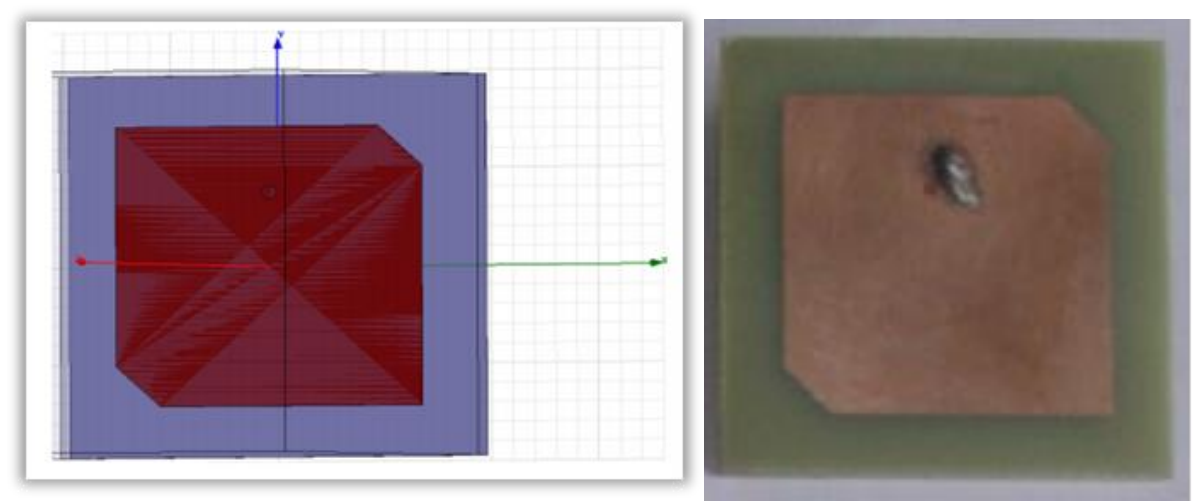

Figure 4. Truncated Corner 
International Journal Of Microwave Engineering (JMICRO) Vol.1, No.4, October 2016

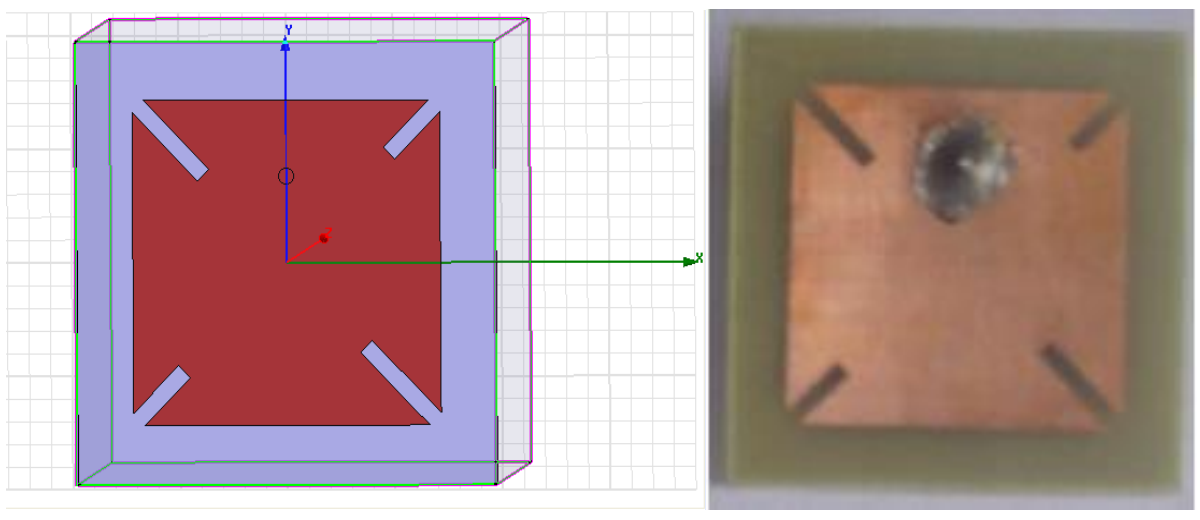

Figure 5. Rectangular Slits

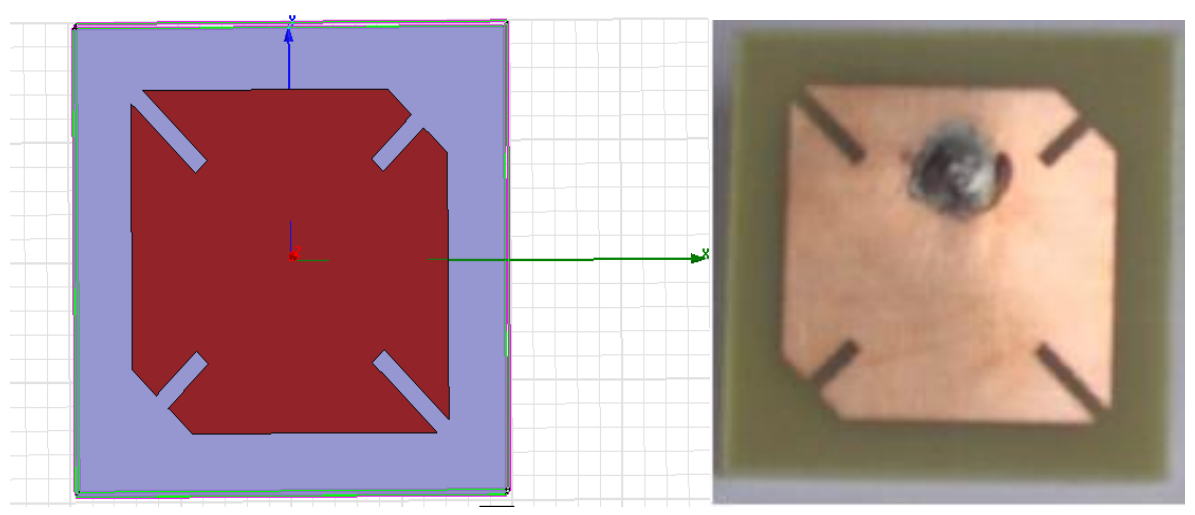

Figure 6. Truncated Corner with Rectangular Slits

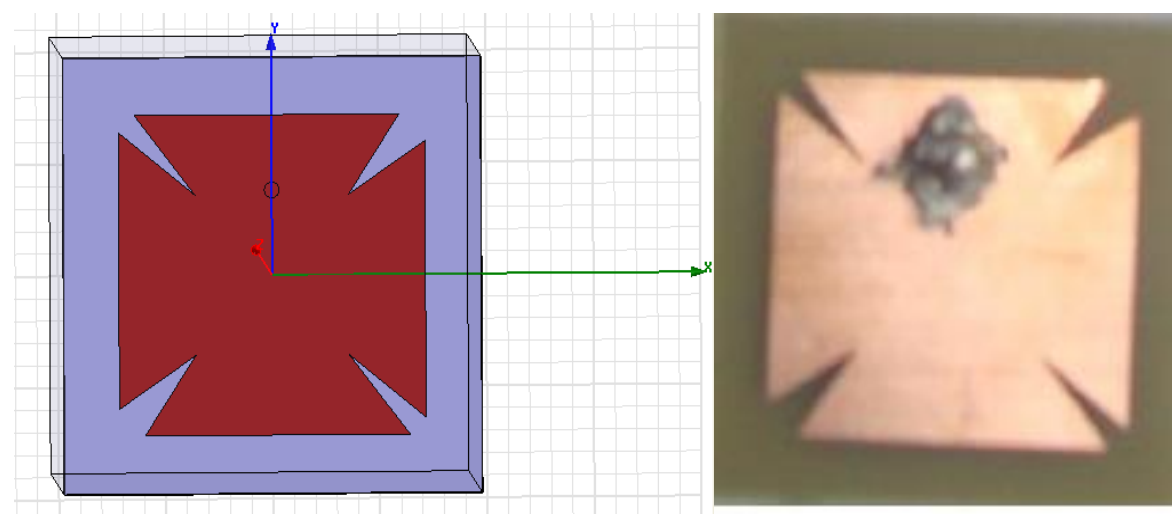

Figure 7. V shape Slits 

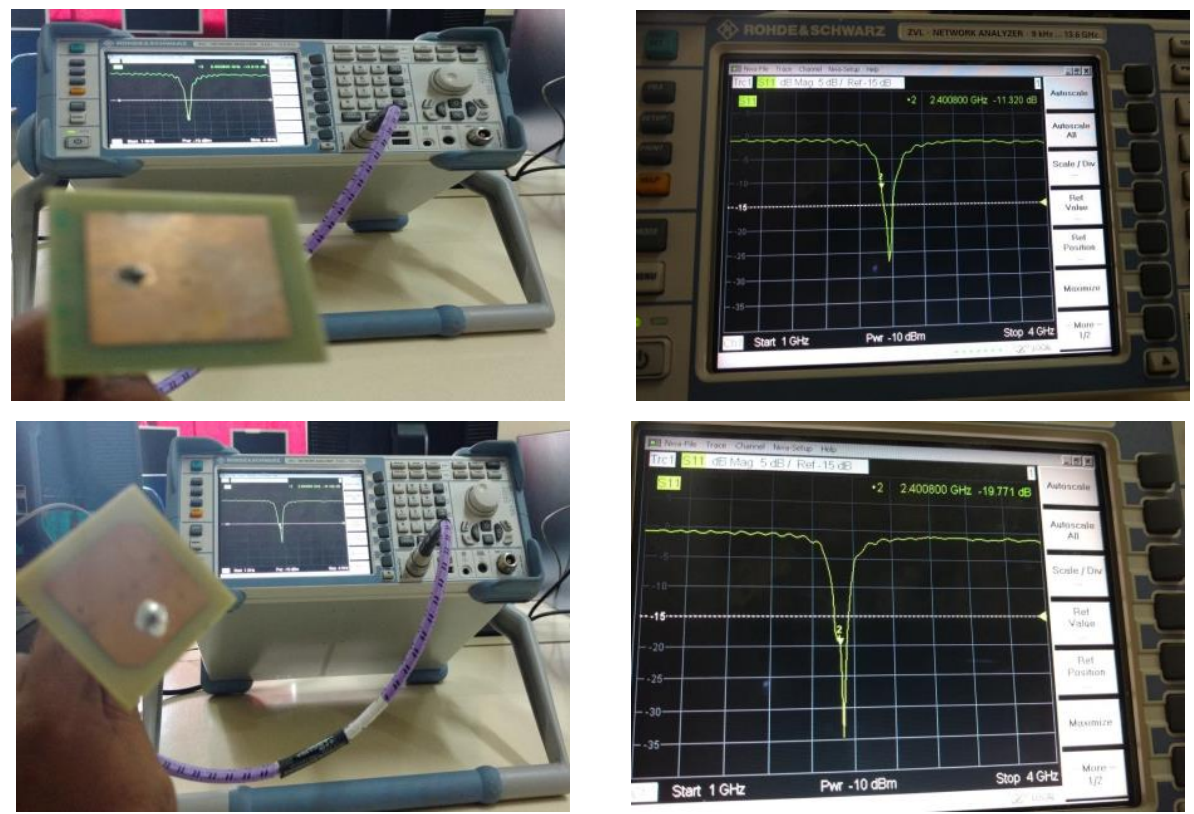

Figure 8. Tesing of antennas on VNA

We tested all the antennas on vector network analyser ZVL $139 \mathrm{KHz}$ to $13.6 \mathrm{GHz}$ (ROHDE \& SCHWARZ) for parameters such as return loss and VSWR as shown in figure 8.

\section{DESIGN METHODOLOGY}

1. Ansoft HFSS was used to simulate and verify following design steps:

- The slit circumference along one of the diagonal axes with respect to the other diagonal axis on a patch radiator was varied to achieve circularly polarized radiation with compact size.

- After comparison of the performance of the antennas based on fixed overall antenna size and patch radiator size, circularly polarized microstrip antennas based on largerperimeter types of slits are more compact.

- Different slit shapes embedded microstrip square patch radiators are studied as follows:
i) Truncated corners
ii) Truncated corners and slits
iii) V-shaped slits
iv) Rectangular slits

- Two resonant modes which are equal in magnitudes and orthogonal to each other are obtained through excitation of the slit along the diagonal direction of the patch. The circumference of the slits in the diagonal directions is changed in order to obtained two orthogonal resonant modes for the circularly polarized radiation.

2. Using HFSS simulation the following parameters were observed: Gain, Return Loss, Radiation Pattern, VSWR, Directivity and Bandwidth.

3. The circularly polarized microstrip patch antenna was fabricated using symmetric slit on FR4 substrate, tested and verified using network analyser for the specified parameters of the antenna.

4. Comparison of hardware results and simulated results. 


\section{SIMULATION AND RESULTS}

The simulated results of return loss, VSWR, axial ratio, radiation pattern of proposed circularly polarized symmetric-slit microstrip antenna operating at $2.4 \mathrm{GHz}$ for the above mentioned dimension is given below:

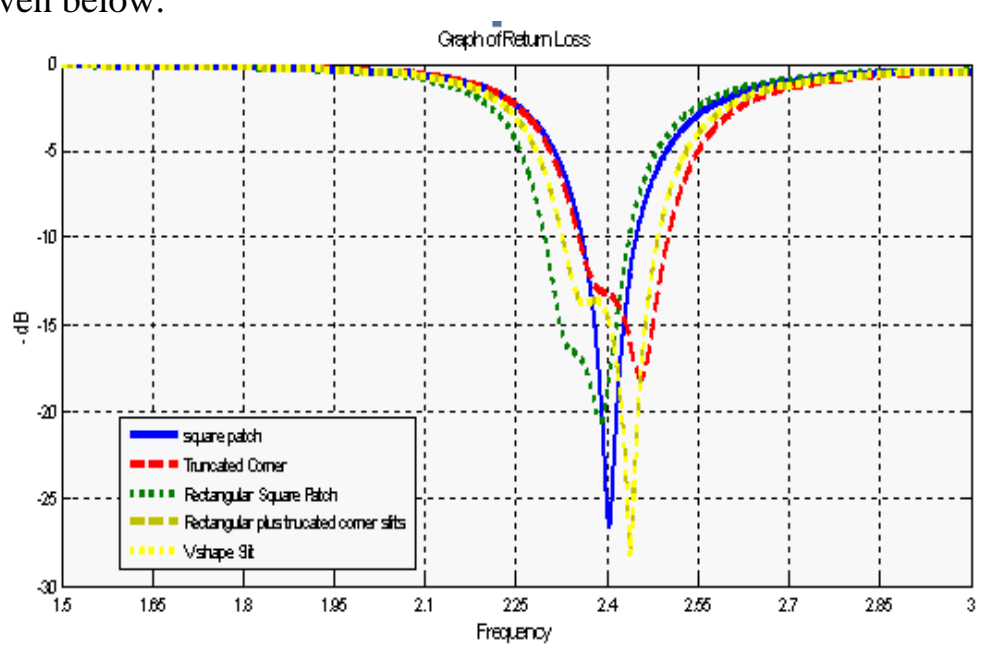

Figure 9. (a) Simulated Return loss Vs Frequency for different antenna structures

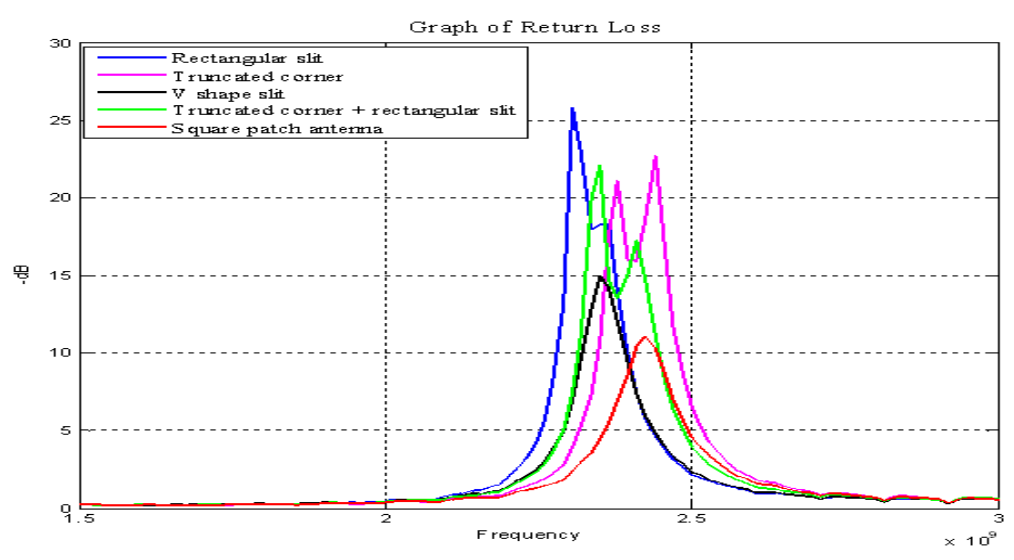

Figure 9. (b) Measured Return loss Vs Frequency for different antenna structures

Figure 9-(a) shows simulated and Figure 9-(b) shows measured results of a return loss with different slit shapes added in main square patch antenna at resonant frequency of $2.4 \mathrm{GHz}$. The bandwidth of rectangular slit with the truncated corner is $158 \mathrm{MHz}$. The improvement in bandwidth of rectangular slit with the truncated corner in comparison with the main square patch is the result of reduction in width of the patch. This reduction of width has resulted in reduced resistance and Q factor hence the bandwidth is improved.

$$
\begin{array}{r}
Q=\frac{R}{\omega_{0} L} \\
B W=\frac{1}{Q \sqrt{2}}
\end{array}
$$


The simulated results of the various slit shape structures designed in this paper shows good agreement with the fabricated results. There are various wireless applications working in this frequency band. Figure 10 and 11 show simulated VSWR and axial ratio respectively for different antenna structures, here VSWR below 2 and axial ratio below $3 \mathrm{~dB}$.

Figure 11 shows radiation pattern of different structures antenna. Also from figure 11, it is clear that radiation pattern of the antennas showing omni directional.

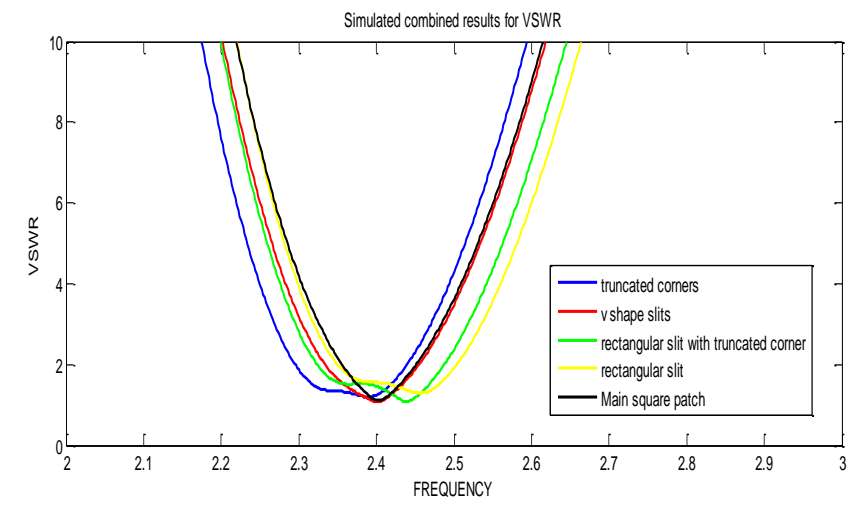

Figure 10. Simulated VSWR Vs Frequency for different antenna structures

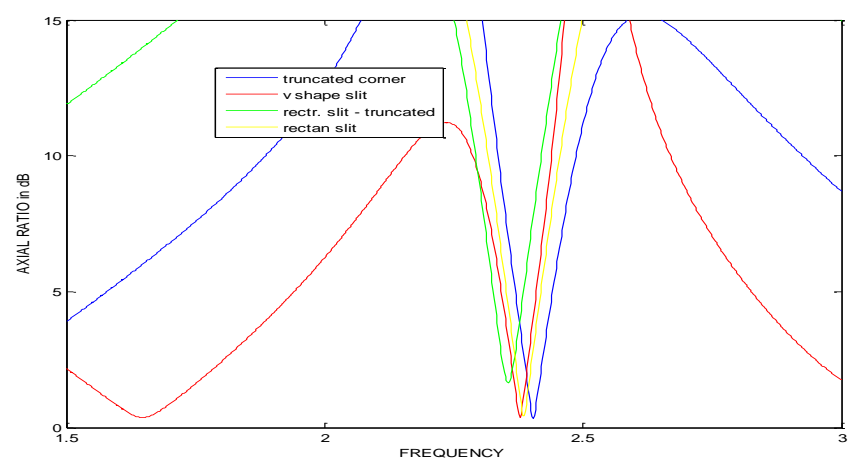

Figure 11. Simulated Axial Ratio Vs Frequency for different antenna structures

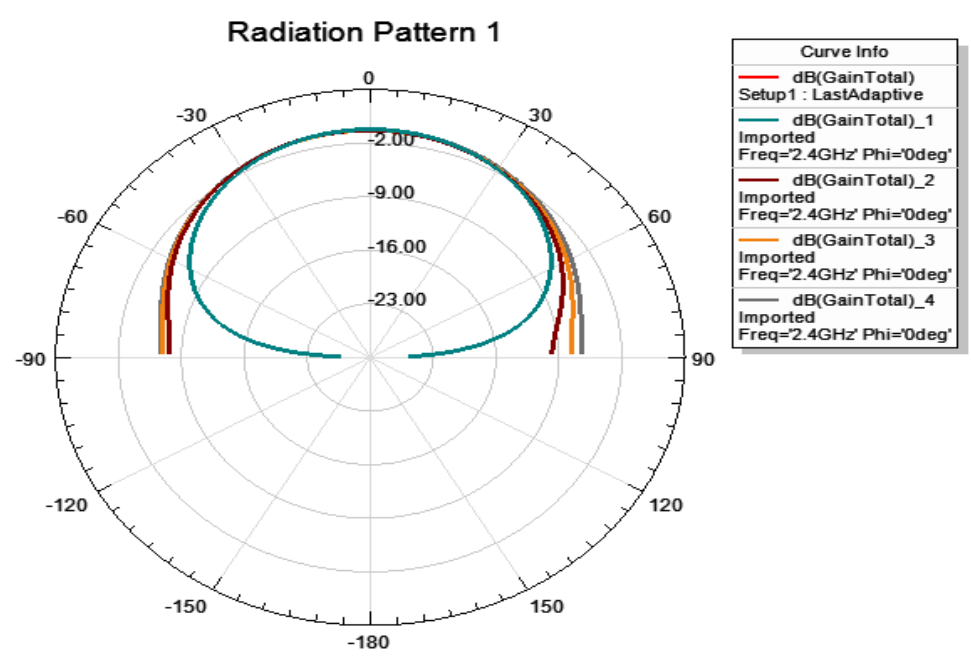

Figure 12: Simulated Radiation Pattern Vs Frequency for different antenna structures 


\subsection{Comparison of the antenna parameters}

Table 2 shows the comparison between simulated results and measured results of fabricated main square patch antenna and other configurations with slits. The table 2 clarifies that there is excellent correlation between simulated and measured parameters of the antenna.

Table 2. Comparison for various antenna parameters

\begin{tabular}{|l|l|l|l|l|l|l|}
\hline \multirow{2}{*}{ Type } & Frequency $(\mathbf{G H z})$ & \multicolumn{2}{l|}{ S $_{11}(\mathbf{d B})$} & VSWR & \\
\cline { 2 - 7 } & Simulated & Measured & Simulated & Measured & Simulated & Measured \\
\hline $\begin{array}{l}\text { Main Square } \\
\text { Patch }\end{array}$ & 2.40 & 2.40 & -26.3 & -11.320 & 1.09 & 1.79 \\
\hline $\begin{array}{l}\text { Truncated } \\
\text { Corner }\end{array}$ & 2.44 & 2.40 & -17.9 & -19.77 & 1.55 & 1.06 \\
\hline $\begin{array}{l}\text { Rectangular } \\
\text { Slit simulated }\end{array}$ & 2.38 & 2.30 & -20.4 & -25.6 & 1.24 & 1.35 \\
\hline $\begin{array}{l}\text { Rectangular } \\
\text { Slit with } \\
\text { Truncated } \\
\text { corner } \\
\text { simulated }\end{array}$ & 2.42 & 2.38 & -28.1 & -21.5 & 1.44 & 1.40 \\
\hline $\begin{array}{l}\text { V shape Slit } \\
\text { simulated }\end{array}$ & 2.40 & 2.35 & -31.2 & -14.9 & 1.06 & 1.43 \\
\hline
\end{tabular}

The parameters in the above table show the improved performance with all added slits compared to the main microstrip patch antenna. From the table 2 it is clear that return loss of rectangular slit with truncated corner is $-28.1 \mathrm{~dB}$.

Table 3 shows the comparison of various parameters of the designed antennas with respect to the following antenna parameters: radiation intensity, bandwidth, directivity and gain. From the table 3 it is clear that rectangular slit added in the main square patch gives best antenna results for radiation intensity, radiated power, accepted and incident power as compared to other slit structures. Rectangular slit with truncated corner structure gives the best results as compared to other slit structures with respect to bandwidth, gain and directivity.

Table 3. Combined results of proposed antennas

\begin{tabular}{|l|l|l|l|l|l|}
\hline Variables & $\begin{array}{l}\text { Main } \\
\text { square } \\
\text { patch }\end{array}$ & $\begin{array}{l}\text { Truncated } \\
\text { Corner }\end{array}$ & $\begin{array}{l}\text { Rectangular } \\
\text { slit }\end{array}$ & $\begin{array}{l}\text { Rectangular } \\
\text { slit with } \\
\text { truncated corner }\end{array}$ & $\begin{array}{l}\text { V } \\
\text { Shape } \\
\text { slit }\end{array}$ \\
\hline $\begin{array}{l}\text { Radiation Intensity } \\
(\mu \text { W/sr })\end{array}$ & 653.2 & 753.44 & 946.5 & 733.95 & 717.74 \\
\hline Directivity & 1.227 & 1.4247 & 1.472 & 1.5103 & 1.493 \\
\hline $\begin{array}{l}\text { Radiated Power } \\
(\mathrm{mW})\end{array}$ & 6.417 & 6.6456 & 8.07 & 6.10 & 6.03 \\
\hline $\begin{array}{l}\text { Accepted Power } \\
(\mathrm{mW})\end{array}$ & 10.06 & 10.244 & 12.8 & 9.8562 & 9.74 \\
\hline
\end{tabular}


International Journal Of Microwave Engineering (JMICRO) Vol.1, No.4, October 2016

\begin{tabular}{|l|l|l|l|l|l|}
\hline $\begin{array}{l}\text { Incident Power } \\
(\mathrm{mW})\end{array}$ & 10.06 & 10.079 & 12.98 & 10.21 & 9.75 \\
\hline Gain & 0.815 & 0.924 & 0.928 & 0.935 & 0.925 \\
\hline Radiation Efficiency & 63.76 & 67.87 & 63.08 & 61.959 & 61.95 \\
\hline Bandwidth (MHz) & 90 & 150 & 140 & 158 & 116 \\
\hline
\end{tabular}

\section{Conclusions}

In this work circular polarization has been achieved in all the configurations of added slits except for the main square patch. The main square patch antenna provides a linear polarization. All the measured parameters have shown an excellent improvement with respect to main square patch antenna. The compactness in the structure has also been achieved. The rectangular slit with main square patch and the rectangular slit with truncated corners give the best results with respect to various parameters. When the rectangular slits are added to the main square patch the bandwidth is improved by 55\%. The bandwidth provided by rectangular slit with truncated corners is $75 \%$ more than that of the main square patch. The gain in the rectangular slit with truncated corner antenna is also improved by $14 \%$ compared to main square patch antenna.

The other parameters such as radiation intensity, radiated power, accepted and incident power are improved in the rectangular slits added to the main square patch. Thus it can be concluded that the addition of the rectangular slits and truncated corners have enhanced the performance of main square patch antenna. Thus we have proposed highly efficient circularly polarized antennas with modified slits added to the main square patch antenna which will be useful to the wireless communication applications fulfilling the requirements of light weight, low cost, small size and low power consumption along with better bandwidth.

\section{REFERENCES}

[1] P. M. Izdebski, H. Rajagopalan, and Yahya Rahmat-Samii, "Conformal Ingestible Capsule Antenna: A Novel Chandelier Meandered Design," IEEE Transactions on Antennas and Propagation, AP-57, 4, April 2009, pp. 900-9009.

[2] B. Hegyi and J. Levendovszky, "Enhancing the Performance of Medical Implant Communication Systems through Cooperative Diversity," International Journal of Telemedicine and Applications, 2010, 2010 , Article ID 920704.

[3] S. D. Targonski and D. M. Pozar, "Design of Wideband Circularly Polarized Aperture-Coupled Micro strip Antennas," IEEE Transactions on Antennas and Propagation AP-41, 2 February 1993, pp. 214- 219.

[4] P. C. Sharma and K. C. Gupta, "Analysis and Optimized Design of Single Feed Circularly Polarized Microstrip Antennas," IEEE Transactions on Antennas and Propagation, AP-29, 6, June 1983, pp. 949-955.

[5] S. M. Kim and W. G. Yang, "Single Feed Wideband Circular Polarized Patch Antenna," Electronics Letters, 43, 13, June 2007, pp .703-704.

[6] S. M. O'Kane and V. F. Fusco, "Printed Curl CP Antenna Design," IEEE Loughborough Antennas and Propagation Conference, 2008, pp .109-1 12.

[7] C. Min and C. E. Free, "Analysis of Circularly Polarized Dual-Ring Microstrip Patch Array Using Hybrid Feed," Microwaves, Antennas \& Propagation, lET, 3, 3, March 2009.

[8] W. S. Chen, K. L. Wong, and C. K. Wu, "Inset Microstrip line-fed Circularly Polarized Microstrip Antennas," IEEE Transactions on Antennas and Propagation, AP-48, 8, August 2000, pp. 1253- 1254. 
[9] W. S. Chen, C. K. Wu, and K. L. Wong, "Novel Compact Circularly Polarized Square Microstrip Antenna," IEEE Transactions on Antennas and Propagation, AP-49, 3, March 2001, pp. 340342.

[10] H. D. Chen, "Compact Circularly Microstrip Antenna with Slotted Ground Plane," Electronics Letters, 38, 13, June 2002, pp .616-6 17.

[11] K. L. Wong and Y.F. Lin, "Circularly Polarized Microstrip Antenna with a Tuning Stub, ” Electronics Letters, 34, 9, April 1998, pp 831 -832.

[12] M. L. Wong, H. Wong, and K. M. Luk, "Small Circularly Polarized Patch Antenna," Electronics Letters, 41, 16, August 2005, pp .7-8.

[13] K. L. Wong and J. Y. Wu, "Single-feed Small Circularly Polarized Square Microstrip Antenna," Electronics Letters, 33, 22, October 1997, pp.1833-1834.

[14] Nasimuddin, X. Qing, and Z. N. Chen, "Compact Circularly Polarized Microstrip Antenna for RFID Handheld Reader Applications," Asia Pacific Microwave Conference, December 2009, Singapore, pp. 1950-1953.

[15] R. Garg, P. Bhartia, I. Bahl, and A. Ittipiboon, Microstrip Antenna Design Hand book, Artech House, Norwood, Mass, USA, 2001.

[16] Suvidya R. Pawar, R. Sreemathy, Shahadev D. Hake, "Design and fabrication of circularly polarized microstrip antenna using symmetric "International Journal of New Trends in Electronics and Communication (IJNTEC-ISSN: 2347 - 7334) Vol. 2, Issue. 1, Jan. 2014

[17] Zhongbao Wang, Shaojun Fang, Qiang Wang, and Hongmei Liu, "An ANN-Based Synthesis Model for the Single-Feed Circularly-Polarized Square Microstrip Antenna with Truncated Corners", IEEE Transactions on Antennas and Propagation, 2012

[18] Constantine A Balanis, "Antenna Theory: Analysis and Design" $3^{\text {rd }}$ edition, (April 4, 2005)

[19] Thomas A. Milligan "Modern antenna design" 2nd edition John Wiley and Son, Inc.2005.

[20] David M. Pozar "Microwave and RF design of wireless system” John Wiley and Son, Inc.2001.

\section{Authors}

Suvidya Pawar received his Bachelor of Engineering degrees in Electronics Engineering from Shivaji University, in 2007 and the Master of Engineering degree in Electronics and Telecommunication (Microwave) in 2013 from Pune University. He had ten months of industrial experience. Since July 2008, he has been working with the Electronics and Telecommunication Engineering Department, PICT, Pune.

Dr. R. Sreemathy is working as Associate Professor in E\&TC Department of Pune Institute of Computer Technology. She received her Post Graduate degree in Electronics Engineering from COEP, Pune and her Doctoral degree from Shivaji University. She has more than 25 years of teaching experience. She has more than 30 paper publications in International conferences and Journals. Her areas of research include Signal Processing, Artificial Intelligence and Wireless Communication.

Shahadev D. Hake received the Bachelor of Engineering degrees in Electronics and Communication Engineering from Dr. BAMU, Aurangabad University, in 2009 and the Master of Engineering degree in Electronics and Telecommunication in 2011 from Pune University. Since December 2011, he has been working as Assistant Professor in the Electronics and Telecommunication Engineering Department, PICT, Pune.
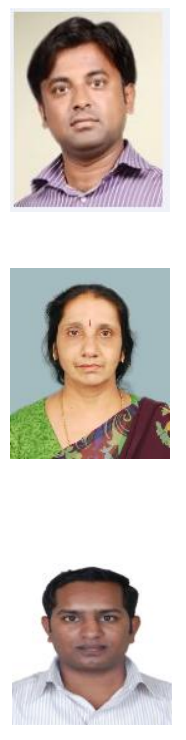